\title{
Factors affecting the outcome of maternity care 1. Relationship between staffing and perinatal deaths at the hospital of birth*
}

\author{
JOHN STILWELL, ${ }^{1}$ ALA SZCZEPURA, ${ }^{1}$ AND MIRANDA MUGFORD²
}

From IMRAD, University of Warwick, Coventry, CV4 7AL and National Perinatal Epidemiology Unit, ${ }^{2}$ Radcliffe Infirmary, Oxford OX2 $6 H E$

SUMMARY This is the first of two papers describing a retrospective study of maternity hospitals in an English health region using data for the years $1977-83$. The research was designed to investigate the relationship between resources (such as staff and equipment) and the outcomes of births at maternity units. Considerable variation in medical and nursing staffing levels in the units in the study was observed. Regression analysis suggests that, after taking account of differences in very low weight births at each unit, the level of paediatric staffing at a maternity unit is a significant factor in explaining differences in "in house" mortality. There was no identifiable relationship between staff categories other than paediatricians and the rate of perinatal death at the hospital of delivery. As selective referral and transfers between hospitals may affect the interpretation of these findings, a second paper follows presenting the results of a further analysis that adjusts both resources and outcomes to take account of neonatal transfers.

National interest in the provision of services for maternity and neonatal care was intensified by the publication in 1980 of the Social Services Committee's report on perinatal and neonatal mortality. ${ }^{1}$ This report recommended, among other things, that standards should be set for appropriate levels of staffing and facilities for maternity care. The government did not directly support this recommendation in their reply to the report, ${ }^{2}$ but the Department of Health and Social Security was simultaneously considering what information would be required routinely to monitor performance in the health services. ${ }^{34}$ Other bodies were studying the information needs of the maternity services in particular. ${ }^{5-7}$

The degree to which such data can inform decisions about the best organisation of maternity care depends on how well the relationship between the factors involved is understood. Although many authors ${ }^{8-15}$ suggest that health resources for perinatal care play an important part in reducing the risk of mortality, there has also been research ${ }^{16-21}$ which appears to contradict this finding for certain groups of births or for certain categories of resource. Economists have also studied maternity hospital resource organisation and "productivity", but these studies have often been

*Crown copyright reserved limited by lack of data about outcomes, having considered only activity levels and throughput in hospitals. ${ }^{22}{ }^{23}$ While such studies may be acceptable to some hospital administrators and may help us to understand crude resource constraints, they can tell us little about whether the resources achieve or contribute to the desired objectives of maternity and neonatal care. This paper describes a study that was set up to investigate whether the mortality risk of babies is related to the resources available for their care at the time of birth. The study had the secondary purpose of identifying sources of routinely collected statistics that could be useful when perinatal services at different units or districts are being monitored and compared.

\section{Materials and methods}

\section{HYPOTHESIS}

We planned to test the hypothesis that there are one or more variables, reflecting staff availability, which improve on the proportion of variation in mortality between maternity units which is "explained" in linear regression by the proportion of low weight births alone. Our study was prompted by an earlier, unpublished study ${ }^{24}$ of seven hospitals in 
Birmingham, in which perinatal mortality was positively associated with medical problem scores for the births at the unit, and negatively associated with staffing levels.

HOSPITALS AS THE UNIT OF ANALYSIS

The choice of the maternity hospital as the unit of analysis presents many problems of interpretation arising from the medical and social selection processes by which women come to deliver at a particular unit. Epidemiological studies of facilities available to populations resident in reasonably large geographically defined areas may correct this bias as women are less likely to be selected for their place of residence on the basis of factors affecting successful childbearing. However, such an approach does not allow analysis to take account of the effects of interaction between different kinds of resources within a particular unit. Nor does it take account of the interrelationship between risks for different births at the same hospital, for example, if high risk cases take resources away from low risk cases. In England and Wales, the maternity hospital unit is the usual unit for routine data collection, particularly about resources, because it is often a unit of management. Because of the difficulties of ascribing resources to resident populations, and given the constraints imposed by the available data, we have chosen the hospital of birth as our unit of analysis.

Maternity hospitals in England are not a homogeneous category, as they include units which are for low risk deliveries only, staffed mainly by midwives under the medical responsibility of general practitioners (GP units). At the other extreme there are centres where specialist skills are available to care for rare maternal or neonatal disorders. Because most GP units have very small numbers of births, and in order to achieve a more homogeneous sample, we excluded isolated GP units from our analysis. For the same reason, we excluded the regional neonatal and obstetric referral unit. Finally, we had to exclude one other unit because it did not contribute to the regional Hospital Activity Analysis (HAA) system. Our study was therefore based on the remaining 20 units with consultant obstetric beds in the West Midlands Region for the years 1977-83.

\section{INDICATORS OF RISK}

The best indicators available to us about the risk status of the births at each unit were the birthweight distribution and whether the birth was singleton or multiple. We considered two alternative measures for birthweight distribution: the proportion of total births at the unit weighing less than $2501 \mathrm{~g}$ (low weight births) and the proportion of total births weighing less than $1501 \mathrm{~g}$ (very low weight births).
Previous evidence suggested that the latter measure would provide a more stable estimate of high risk births across heterogeneous populations than would the proportion of births weighing $2500 \mathrm{~g}$ or less. This is because the "natural" distribution of weights seems to vary between ethnic population groups, ${ }^{25}$ and so a $2500 \mathrm{~g}$ cut off point for each unit may include a varying proportion of infants who are not significantly below the mean weight for their own ethnic group and are thus not at higher average risk of dying. However, the very low weight group is more likely to represent the "abnormal" tail of the distribution in any population.

Nationally, congenital malformations account for around one fifth of perinatal deaths. ${ }^{26}$ The data available for births in West Midlands hospitals also allowed us to identify those deaths occurring during the period of our study when congenital malformations were identified. If there is a relationship between resources and perinatal or neonatal mortality, it is likely that it is less strong, or follows a different pattern, in the case of malformed infants. Any underlying relationship between resources and outcomes in our study might therefore $\frac{\vec{D}}{\vec{G}}$ be clearer if we excluded deaths from malformations. $\bigcirc \mathrm{T}$ As multiple births carry a higher risk than singletons, $\stackrel{\Phi}{\circ}$ 음 we have also looked at differences after excluding $\sigma \overrightarrow{<}$ multiple births from the mortality figures.

\section{OUTCOME MEASUREMENT}

The hoped for outcome of any delivery must be a healthy mother and infant. Within the constraints of our study we could not look at morbidity in mothers and babies, and we were restricted to a study of mortality. For each maternity unit therefore we counted stillbirths (born dead after the 28th week of pregnancy) and early neonatal deaths (within one week of live birth). In this paper, we present analyses based on deaths occurring at the hospital of birth, as is the common practice in the obstetric reports prepared by individual maternity units. In the paper that follows, we describe the effects of including deaths occurring after the first week and also those occurring after transfer to another hospital.

\section{MEASURING RESOURCES}

Debate about the appropriate choice of indicators of the quantity or quality of perinatal care has paid little attention to actually measuring the inputs to care. Maternity care is not a fixed technology, and a similar "level" of care may be provided in different centres by different proportions of nurses, midwives, and obstetric and paediatric staff, with varying amounts of equipment. Categorisation of these different groupings of resources into levels of care is usually based on clinical judgement and to some extent 
prejudges the question of whether different amounts of specific resources affect outcome. In the study described here, we have looked separately at the components of resources in units that might all fall into the "level 2" category of care, as they are mostly district consultant obstetric units with special care facilities for sick newborns.

As staff represent the largest single cost to maternity services, and as staff levels had previously been found to be a possible explanatory factor, we concentrated on describing categories and grades of staff at the units. Separate data were sought about the following categories of staff: state certified midwives, by grade; nurses without SCM qualification, by grade; medical staff, by grade, in the specialties of obstetrics and gynaecology and paediatrics. A work study of midwifery and nursing staff presence and activity in different units based on actual observations has been carried out by the DHSS and published as an internal report. ${ }^{27}$ It was our intention, however, to make full use of routine sources. To be consistent with what is routinely collected at national level we therefore measured midwifery and nursing staff available by an average of numbers of whole time equivalent staff in post on 30 March and 30 September in each year of the study, and medical staff by numbers in post on each of these dates.

The selection of data items for description of resources available at each unit was based on recommendations of various professional and health service bodies concerned with perinatal services, in particular, a joint standing committee of the British Paediatric Association and the Royal College of Obstetricians and Gynaecologists, and the working groups of the Information Services Group. In addition, items of data that might be useful in a regional review of perinatal services have been identified by one of us in a study of the content of those regional reviews that have taken place. ${ }^{7}$ Routine sources cannot tell us very much about the equipment, building, and access to services at each maternity unit; therefore our survey also asked about availability of "on site" services, availability of "off site" services, including "call out" and travel times, and a list of items of equipment available in obstetric and neonatal units.

\section{DATA COLLECTION}

The study was carried out in the West Midlands Region, as a retrospective observational study of births that occurred between 1977 and 1983 . Routinely collected data were obtained with the help of the West Midlands Regional Health Authority. It was necessary nevertheless to collect some data directly from the maternity hospitals included in our study. The senior midwife at each unit helped us by completing a questionnaire about the unit's staffing from 1977 to 1983 , about facilities, and about access to services both within and beyond their own hospital site. Most hospitals in the region contributed to the regional Hospital Activity Analysis (HAA) maternity system, and thus data were available at regional level about the births, including birthweight and presence of malformation, and the outcome of the births at these units. Two large maternity hospitals kept their own data systems and did not contribute to the regional system. Data about the births in these hospitals were collected directly. The HAA data were supplied on computer tape by the West Midlands Regional statistician and analysed by the authors using the university computers at Oxford and Warwick.

All health regions are required to collect and return annual statistics about medical and nursing staff to the DHSS. This annual staff census provides a breakdown by category of staff and grade. Data about nursing, midwifery, and medical staff were available at the West Midlands Regional Health Authority. As these data did not allow us to relate all staff to individual units, or even to identify numbers of medical staff, we were obliged to ask each maternity unit surveyed for this information. Even so, at several units, data for medical staff at consultant level in the period studied were still limited to a "head count" of staff. Furthermore, it was not possible to differentiate between staff within specialties and so, for example, we could not count separately full-time neonatologists and other paediatricians.

\section{DATA VALIDATION}

There have been considerable criticisms of many routinely collected data systems. Hospital Activity Analysis, for example, has been shown to contain significant coding errors. ${ }^{28}$ We were aware of these possible shortcomings and indeed encountered them. For example, when we compared figures from two sources for total births in West Midlands hospitals for the years of our study we found that the HAA count of total births differed by up to $5 \%$ of the total provided for the annual Hospital Return (SH3). We also compared data about midwifery staff from our survey of units with those available from the regional manpower statistics. We found that the figures were similar but not the same. This may be explained partly by delays in updating the payroll when staff move between grades or units. Developments since 1983 in manpower data systems may have reduced these discrepancies.

We were obliged to use the HAA data for our study, but for staff data we chose to use the figures given at unit level, preferring to rely on senior unit staff having a better idea of their own unit's personnel than to 
assume that the processed payroll statistics would be accurately coded. Inevitably, some data items were not available for all units in each year covered in the study. In these circumstances, the unit in question had to be excluded from the regression analysis for that particular year.

\section{ANALYSIS}

We have already used the data from this study to introduce a graphical method for presenting information on outcomes and resources to maternity managers at unit level. ${ }^{29}$ This approach may offer an intuitive indication of which factors are likely to be important in influencing a particular outcome. For the present study, however, we considered a set of linear models in which we used multiple regression analysis to investigate statistical relationships between measures of mortality as dependent variables, and staffing measures and birthweight distribution as explanatory variables. (The detailed specifications for the regressions are given in the Appendix to this paper, and definitions of the variables used in our analyses are given in Appendix table A1.)

We analysed data for each of the years 1977 to 1983 separately. This ensured that we did not force a constant value for the coefficients of the explanatory variables over time, nor make prior assumptions about the effects of time trends in particular variables. (Appendix table A2 specifies the variables considered in each such series of analyses.) We looked first at crude perinatal mortality (PNMR) and the effect of different combinations of staffing and different measures of low weight births on the regression equation. The second set of analyses is restricted to deaths among singleton births (SPNMR). The third set of analyses excluded deaths where the first "condition code" recorded on the HAA record was for congenital malformation (PNMRCA). Perinatal deaths were separated into stillbirths (SB) and first week deaths (FWD) in the fourth and fifth sets of analyses, and the sixth set of regressions were for first week deaths excluding malformations.

The explanatory variables have been described above and in the appendix. In all but the first two analyses, we considered two measures of low weight birth simultaneously. Staffing variables were chosen to reflect each of the three main skilled clinical groups responsible for the care of mothers and babies at the time of birth and immediately afterwards: midwives, obstetricians, and paediatricians. Numbers of staff were expressed as a ratio to total births in the unit (MN, OB, PD).

The variable $\mathrm{MN}$ measures all qualified nursing and midwifery staff at each unit. Although we recognise that midwives are more likely than nurses without SCM qualification to be directly responsible for aspects of care which could directly affect perinatal mortality, we assumed that it would be the total complement of nursing and midwifery staff that would best reflect their ability to act well in this capacity. However, we also looked at the effect of variation in the ratio of qualified midwives alone (SCM) in one analysis. As paediatricians are likely to spend a higher proportion of their time caring for high risk births, a more appropriate denominator might be the proportion of low weight births. Accordingly, the analyses look at this measure (PD/LBW) as an alternative variable to PD.

Even though we excluded the isolated GP units, the annual number of births in the maternity units studied varied from 800 to over 5000 . We therefore performed the regression analyses including the annual number of births at each unit as a weighting factor.

When the data from the different sources had been prepared in machine readable, compatible form, we performed analyses using the SPSS-X statistical computer package. Inspection of scatter diagrams and correlation matrices allowed us to observe interactions between variables in our analyses. We used stepwise linear multiple regression to identify which, if any, of the staffing and birthweight variables best explained variations in mortality between maternity hospitals. The approach to multivariate analysis which we have followed is described, with well advised caution about interpretation, in an article by Lew and colleagues in the Journal of the American Medical Association. ${ }^{30}$

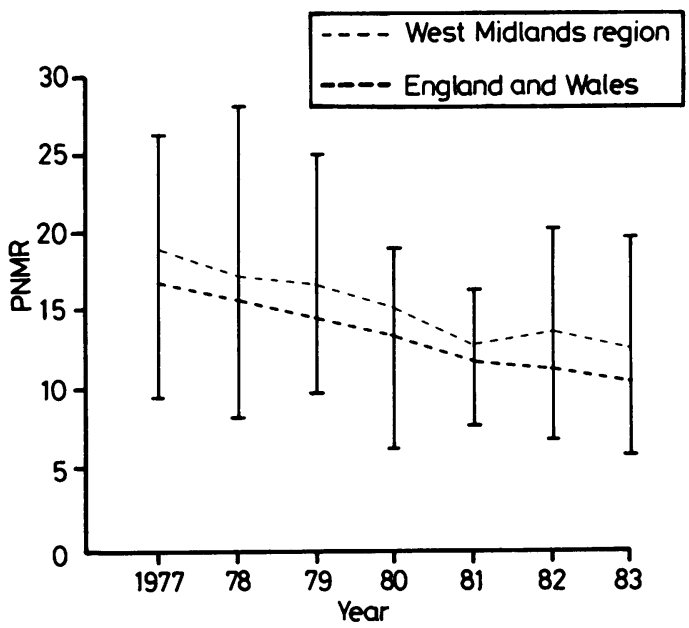

Fig 1 Trends in perinatal mortality in West Midlands maternity units, 1977-83. 
Results

\section{PATTERNS AND TRENDS}

\section{Mortality}

Between 1977 and 1983 perinatal mortality for births to residents in the West Midlands fell from 19.0 to 12.3 per 1000 total births. The range of mortality rates in the hospitals included in this study was wide. Rates for individual hospitals fluctuated over time though they generally showed a downward trend (fig 1). The variations partly reflect the relatively small numbers of deaths at each unit but also differences and changes in "case mix".

\section{Birthweight}

The median proportion of very low weight births in West Midlands obstetric units varied but was close to the national percentage at around $1 \%$ of births. Over the period from 1977 to 1983 the range has increased (fig 2). Possible explanations may include increasing selection for place of birth over the period (including in utero transfer). The inclusion of increasing numbers of births of less than $1000 \mathrm{~g}$ in the birth statistics could also affect the upper value.

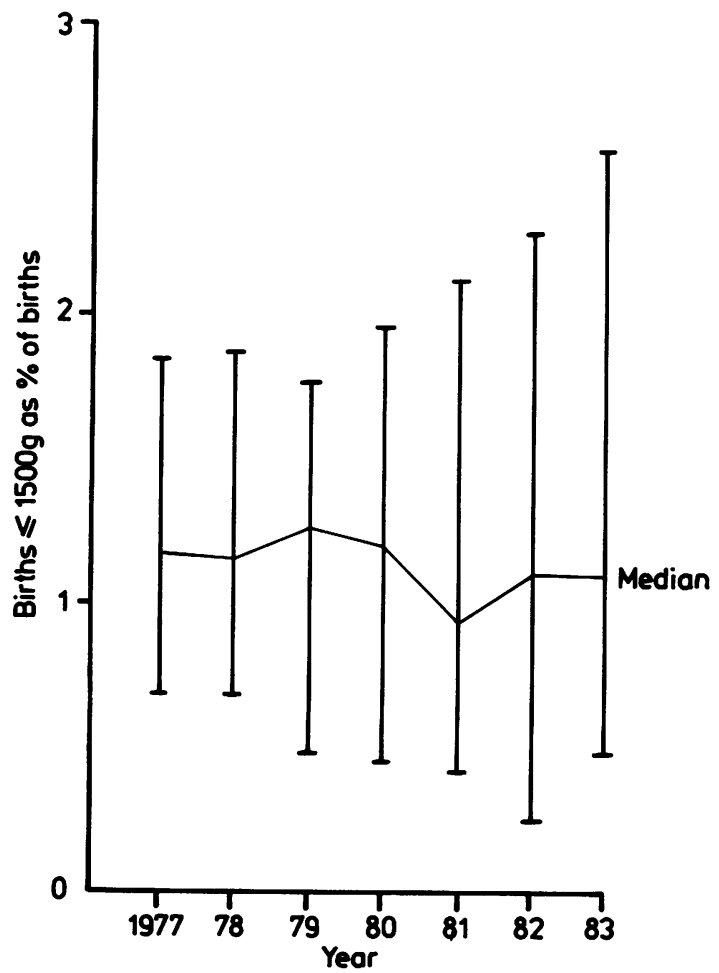

Fig 2 Maximum and minimum percentages of births weighing $1500 \mathrm{~g}$ or less, West Midlands maternity units, $1977-83$.
Numbers of births

The range of annual numbers of births in the obstetric units studied varied by a factor of six, the majority of units falling into the range $1000-5000$ annual births. The regional crude birth rate increased from 11.8 in 1977 to 13.2 per 1000 total resident population in 1983 , with a peak in 1980 . However, births in individual hospitals did not always follow this pattern, being affected also by neighbouring unit closures or changes in referral patterns.

\section{Medical staff}

Ratios of medical staff of all grades per 10000 births in the specialties of paediatrics and of obstetrics and gynaecology varied widely between consultant obstetric units in each of the years 1977 to 1983 , with the highest values three times the lowest value (fig 3). In 1982, the ratio of obstetric staff per 10000 births varied between 26 and 37, while the same ratio for paediatric staff varied between 13 and 21 .

\section{Midwives and nurses}

There was also a wide variation (between 14 and 33 per 1000 births in 1982) in the ratio of whole time equivalent midwives to births at each unit. This was not correlated with the size of the unit. There was a slight upward trend in the ratio after 1979 (fig 3). This is likely to be due to the change in 1980 in the whole time working week for midwifery and nursing staff from 40 to 37.5 hours a week. The ratio for nonmidwifery nursing staff per 1000 births varied considerably, between 20 and 35 in 1982, and there was no upward trend for this group.

\section{Interrelationships between factors measured}

In regression analysis, it is important to check whether the explanatory variables are themselves correlated, because if they are it is more difficult to distinguish their separate effects upon the dependent variable. There was little correlation between the different staff categories except in one year (1983) when obstetric and paediatric staff measures were found to be positively correlated with nursing staff.

In most years studied we found that there was strong significant positive correlation between perinatal (PNMR) or first week deaths (FWD) and the proportion of very low weight births. Mortality was also negatively correlated with measures of staffing, that is, mortality rates were lower when staffing ratios were higher. In most cases this correlation was very weak, the only exception to this being the correlation between mortality and paediatricians per low weight birth (PD/LBW). This is illustrated for two typical years in tables la and $1 \mathrm{~b}$, which show that units with 

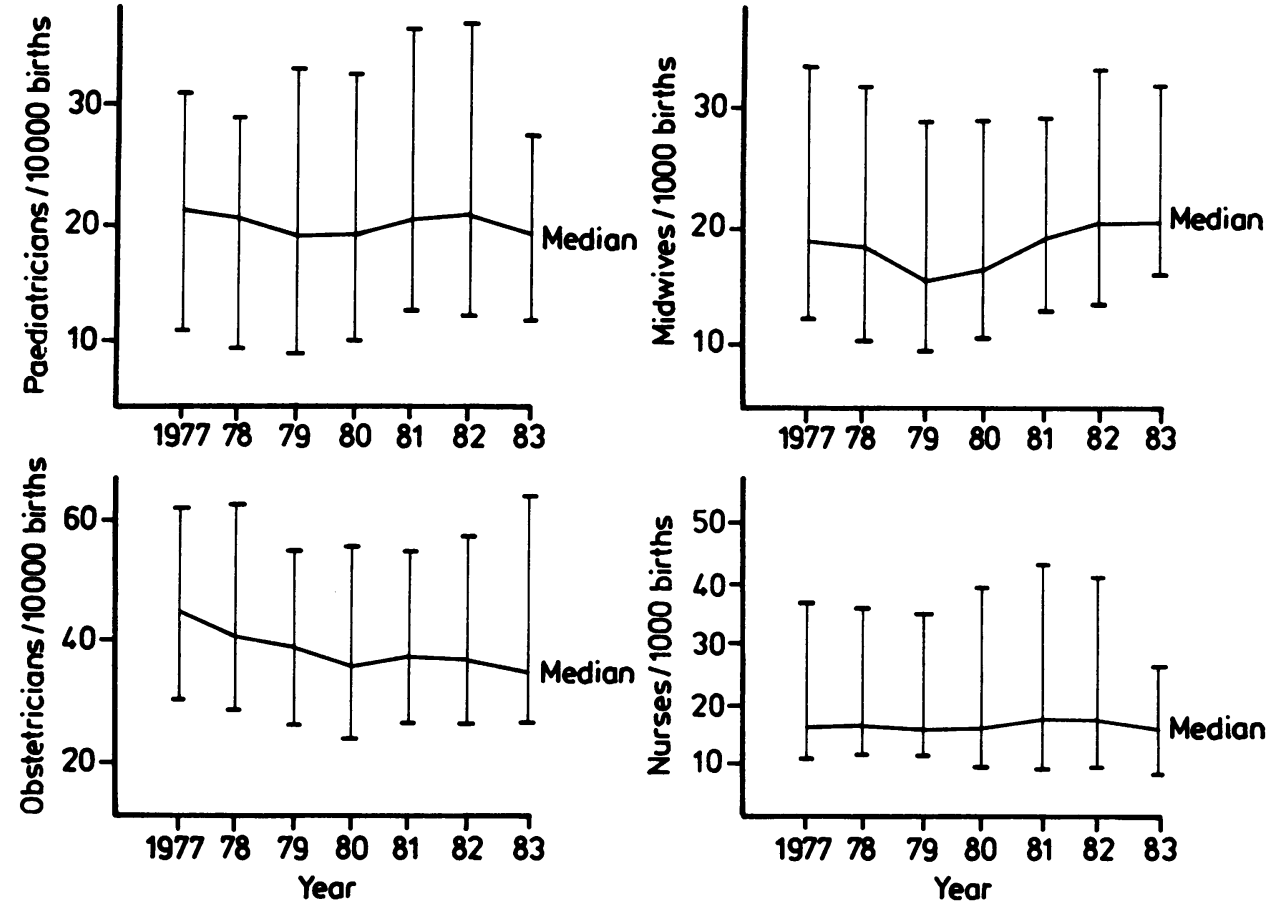

Fig 3 Ranges of staffing ratios at West Midlands maternity units, 1977-83.

high paediatric staffing ratios are unlikely to have high mortality, and that units with higher mortality do not include those with high staffing ratios.

Table 1a West Midlands maternity units grouped by paediatric staffing ratios and "in house" early neonatal mortality rates, 1977

\begin{tabular}{|c|c|c|c|c|c|}
\hline & & \multicolumn{4}{|c|}{$\begin{array}{l}\text { Number of units with "in house" early } \\
\text { neonatal mortality rates of: }\end{array}$} \\
\hline & & Under 7 & 7109 & Over 9 & $\begin{array}{l}\text { All } \\
\text { mortality } \\
\text { rates }\end{array}$ \\
\hline \multirow{4}{*}{$\begin{array}{l}\text { Number of } \\
\text { units with } \\
\text { paediatric } \\
\text { staff per } \\
1000 \text { low } \\
\text { weight births }\end{array}$} & Up to 21 & - & 3 & 1 & 4 \\
\hline & $22-30$ & 1 & 6 & 2 & 9 \\
\hline & Over 30 & 4 & - & - & 4 \\
\hline & $\begin{array}{l}\text { All staffing } \\
\text { ratios }\end{array}$ & 5 & 9 & 3 & 17 \\
\hline
\end{tabular}

As we have shown, the observed correlations suggest that, taken separately, very low birthweight and paediatric staffing were both related to the risk of perinatal death at the hospital of birth in each of the years 1977-83. Multiple linear regression allows us to establish for each year whether or not variations in mortality are related in a linear form to some or all of a
Table $1 \mathrm{~b}$ West Midlands maternity units grouped by paediatric staffing ratios and "in house" early neonatal mortality rates, 1982

\begin{tabular}{|c|c|c|c|c|c|}
\hline & & \multicolumn{4}{|c|}{$\begin{array}{l}\text { Number of units with "in house" early } \\
\text { neonatal mortality rates of: }\end{array}$} \\
\hline & & Under 6 & 6 to 8 & Over 8 & $\begin{array}{l}\text { All } \\
\text { mortality } \\
\text { rates }\end{array}$ \\
\hline \multirow{4}{*}{$\begin{array}{l}\text { Number of } \\
\text { units with } \\
\text { paediatric } \\
\text { staff per } \\
1000 \text { low } \\
\text { weight births }\end{array}$} & Up to 21 & 1 & 1 & 3 & 5 \\
\hline & $22-30$ & 5 & 1 & - & 6 \\
\hline & Over 30 & 8 & - & - & 8 \\
\hline & $\begin{array}{l}\text { All staffing } \\
\text { ratios }\end{array}$ & 14 & 2 & 3 & 19 \\
\hline
\end{tabular}

group of explanatory variables, and to estimate the size and significance of any relationship observed.

In each year there was at least one equation that was statistically significant at the $99 \%$ level. The proportion of total variance in mortality explained by the models varied from 60 to $33 \%$. The models produced sensible constant terms which could be taken to represent "underlying" mortality. This constant averaged 7.22 and generally took a decreasing value in successive years. In all models the signs of coefficients on the explanatory variables 
conformed to expectations, that is, the predicted effect of a higher proportion of low weight births was an increase in mortality, and the effect of more resources was a decrease.

Whatever measure of mortality is used, the variables selected as contributing significantly to the explained variance in mortality included either an indicator of the birthweight distribution, or a measure of paediatric staffing, or both. The measure of the birthweight distribution that was more frequently selected was the percentage of births weighing $1500 \mathrm{~g}$ or less.

A full summary of the regression results is presented in the Appendix, and we highlight some of the important findings in the following paragraphs.

For in house perinatal mortality rates there were two equations which performed well in different years. For the years 1979, 1980, 1981, and 1983 an equation of the following form was found to be the combination of variables that best "explained" variations in mortality in that year (1980 values are given):

PNMR $=7 \cdot 84( \pm 2 \cdot 16)+0.52( \pm 0 \cdot 18) \mathrm{TB} \leq 15$

$r^{2}=0.35 \quad p=0.009$

For 1978 and 1982 the following equation was selected (1982 values are given):

PNMR $=8.06( \pm 2.67)+0.12( \pm 0.03) \mathrm{TB} \leq 25-$ $0.22( \pm 0.08)$ PD

$r^{2}=0.54 \quad p=0.006$

The interpretation of the second equation is that an underlying perinatal mortality rate of about 8 per 1000 total births is increased by 0.12 for every unit increase in the percentage of births weighing $2500 \mathrm{~g}$ or less, and decreased by 0.22 for every unit increase in the ratio of paediatricians to 10000 births.

Similar equations, using either $\mathrm{TB} \leq 15$ on its own or $\mathrm{TB} \leq 25$ together with PD explain variations in singleton PNMR and PNMR excluding malformations, with similar values for the coefficients. Thus the regression equation for 1982 for "in house" non-malformed perinatal deaths per 1000 total births is:

PNMRCA $=16 \cdot 5( \pm 1 \cdot 8)-195( \pm 61)$ PD/LBW

$r^{2}=0.42 \quad p=0.006$

For first week deaths, the most satisfactory model for $1977,1978,1980$, and 1982 was as follows (1982 figures are given):
FWD $=9.78( \pm 1 \cdot 14)-177 \cdot 48( \pm 39 \cdot 21) \mathrm{PD} / \mathrm{LBW}$

$r^{2}=0.59 \quad p=0.0005$

We observed this relationship in more than half of the years studied, and this suggests that we are observing a real phenomenon and not just a chance association.

Where the variable $\mathrm{PD} / \mathrm{LBW}$ is included, we find no birthweight measure separately selected in the regression. This variable was designed as an indicator of paediatric cover for babies "at risk", and for use in the equations that excluded stillbirths. When we offered it as an explanatory variable for perinatal mortality, we found that it explained almost as much of the variance as the equations given above. This was consistent with our finding that the stillbirth rate was predicted by none of the variables in our models, whether or not we included those with congenital malformations.

The obstetric, midwifery, and nursing variables were not selected by any of the regressions. Changing the midwifery and nursing variable to include only qualified midwives did not alter this pattern (row $1 \mathrm{c}$ in table A2). However, where more detailed staffing data were available (12 units), the correlation coefficients suggested that subsets of the variables $O B$ and $M N$ may have an effect that was lost in the more general measure. Given the small number of units with such detailed data, the probability of detecting statistically significant relationships was reduced. This was borne out in regression analysis where no significant relationships were detected.

\section{Discussion}

This study set out to examine the relationships between staffing at maternity units and the outcome of birth, and also to consider the usefulness of routinely available statistics for monitoring maternity services. Our analysis has yielded some potentially important findings, which we discuss below. We also consider some points about design and use of routine data systems for monitoring maternity and neonatal care.

In this study, we chose to use a multivariate regression model including measures of birthweight distribution as an independent variable, instead of the alternative approach which examines birthweight groups separately. This was because we thought we might find an effect whereby a heavy workload, signalled by a higher proportion of low birthweight deliveries, might influence the death rate of all babies, including bigger ones. Our analysis did not support this: there was no relationship between death rates for babies weighing over $2500 \mathrm{~g}$ and the birthweight distributions. 
The observation that "in house" perinatal mortality was dependent on the proportion of births within the group weighing $1500 \mathrm{~g}$ or less confirmed our hypothesis that this was a more sensitive indicator of births at risk than the proportion weighing $2500 \mathrm{~g}$ or less.

STAFF AT THE HOSPITAL OF BIRTH AND PERINATAL MORTALITY

Many claims have been made about the inadequacy of staffing and facilities at the place of birth, and calls have been made for standards to be set. We found that there were wide variations in ratios of professional staff caring for women and their babies at each unit, but that in only one case, that of paediatric staff, was there a consistent relationship between staffing ratios and mortality rates. This was significant in four of the seven years studied.

The lack of a clear relationship between mortality and obstetricians and/or midwives suggests two points. One is that a large proportion of the work in the units studied, particularly for midwives, is caring for women giving birth to those babies who are at the lowest risk of death. Bakketeig and colleagues ${ }^{8}$ found in Norway that for the low risk group there was a minimum level of resources below which mortality increased, but above which increases in resource levels had no effect on mortality. If this pattern applied in our study we could conclude either that all units had at least the threshold level for midwifery and obstetric staffing, or that deaths in this group are so rare that we could not have observed any effect if it did exist, given the small number of units studied.

Following on from this point, we do not conclude that additional staff who have not been shown to be "saving more lives" are not performing a useful purpose. More appropriate measures of the outcome of maternity care would be needed before we could comment on the effects of the wide range of obstetric and midwifery staffing at the units in our study.

Although examination of all newborns is part of the work of paediatricians in maternity units, their rôle is inevitably focussed on sick and low weight babies. Paediatricians were less numerous in maternity units in our study than obstetric staff, making it possible for units to be left with no senior paediatric cover, or for junior staff to be available only on a one in two rota. It is perhaps not surprising therefore that early neonatal deaths should be more sensitive to the level of paediatric staffing. In England and Wales as a whole, there has been a steady increase in the ratio of paediatricians to births over the period of our study, 27.3 per 10000 livebirths in 1977 to 34.8 in 1982 . This was not true for the units studied in the West Midlands Region (see fig 3).
During this period there has been an increasing emphasis on neonatal care and appropriate referral. Evidence from our study suggests that in utero and neonatal referral between hospitals has been increasing steadily. Thus it is not just staff and workload at the place of birth that may be important but also facilities available to those births at district and regional level.

BIRTHWEIGHT AND PERINATAL MORTALITY We accept that birthweight alone may not completely control for social or ethnic risk factors. If it were the case that well staffed units also serve the socially better favoured populations, correlation between staffing and mortality would be artificially strengthened. In the case of ethnic differences, we found that unit staffing figures for 1980 were not related to the proportion of district births where the mother was born outside the UK. If there is a confounding effect from these variables, it must be because of selective cross boundary referral of less risky births to better staffed units or lower referral of high risk births from poorly staffed units. The available data did not allow any more complex investigation of such selective referral biases.

ROUTINE SYSTEMS FOR MONITORING MATERNITY AND NEONATAL CARE

It was an aim of this study to use routinely collected data where possible. We have done this, and confirmed that there are shortcomings in what is measured, in the availability and flexibility of data, and in its completeness. Because information and data collection are currently at the forefront of health authority activity, it may be a good time to emphasise factors that could make the data more useful.

\section{Patient information}

Monitoring regional services, and following cases between districts, would be simplified if all units contributed to a compatible patient information system. Confidence in such a system might be improved if clinical staff in those units contributing records were asked to check the accuracy of their data, at least by feedback of regular summaries. Elsewhere we have suggested one approach to this problem. ${ }^{29}$

For monitoring maternity services and outcomes, there are equally good and diverse reasons for tabulating results by administrative unit, hospital of birth, or by residential area, and a data system should have the flexibility to do this. Such analyses will help to establish the extent to which selection for place of 
delivery accounts for mortality differences, and would allow assessment of which facilities are in fact available to their local populations.

A maternity information system should also be designed to trace outcome after the hospital episode during which birth occurred. Analysis of all the neonatal deaths recorded in the West Midlands Regional HAA in 1982 showed that of 453 recorded neonatal deaths in West Midlands hospitals, 14\% (64) occurred after neonatal transfer. At present, linking these deaths to the birth record is a complex process, but we have done this for the years 1978, 1980, and 1982. The results of incorporating deaths after transfer into our analysis will be reported later.

\section{Information about staff}

The recommendations from the NHS/DHSS Information Steering Group, if implemented fully, should go a long way to improving statistics about staff. It is not clear, however, whether this will permit the analysis of medical staff time within each specialty. At present we cannot exclude the time spent on gynaecological or general paediatric care by the medical staff included in our study, and thus our medical staffing figures provide only a crude estimate of resources for maternity care. Planned medical manpower systems should allow analysis at regional level of whole time equivalent staff available for each unit in the region.

\section{Conclusions}

For the past 20 years or so, measurement of the effectiveness of the perinatal services has concentrated on the "hard" measure of mortality. Explanatory variables for variations in mortality have been birthweight, social class, and other factors related to living conditions. Studies have tended to take the district or larger geographical unit as the basis for analysis, and these may well be the most appropriate explanatory variables in these circumstances. Our study, however, examines outcomes at hospital level, and it is at this level that variations in the provision of resources might be expected to have a discernible impact on outcomes. We have been able to conclude from our study that not only is the variation in perinatal mortality primarily associated with the proportion of births weighing under $1501 \mathrm{~g}$, but that higher paediatric staffing levels are associated with lower mortality rates. Predictably, this effect is most marked when the mortality measure is early neonatal death. Our results would indicate that, within the West Midlands, a maternity unit with relatively low paediatric provision and approximately 3000 births a year could have prevented two first week deaths in a year by employing an additional paediatrician.

Mortality in most maternity units is now so low that it may be questioned whether it will remain a suitable indicator at unit level. We have shown that there are wide variations in resources that are not associated with differences in mortality rates. It follows therefore that, unless units vary to a hardly credible extent in their efficiency of resource utilisation, there must be variations between units in other as yet unmeasured indicators. For example, future morbidity in mothers or infants, and mothers' satisfaction with their care, may be related to volume of resources. The causes of individual deaths are likely to be found in special factors operating at local level, and these will be identified by audit of a kind which is now widespread in health districts. ${ }^{31}{ }^{32}$ Although collation of these data at regional and national level will provide useful epidemiological insights, they cannot be used for routine monitoring of maternity services at district level or below. Studies designed to develop and standardise measures of morbidity and consumer satisfaction are now necessary before research on optimum resource use in the maternity sector can be taken any further.

We thank all those who helped in our research: staff at West Midlands Regional Health Authority, Manpower and Computing Sections, for advice and data; all those at the districts and units studied who responded to our questions; Alan Lodwick for computer programming; staff at both the Warwick and Oxford University Computer Services for advice and help; and our colleagues at the National Perinatal Epidemiology Unit and elsewhere for comments on our work. We thank Lesley Mierh, Myrna Holmes, and Jini Hetherington for typing help. The research was funded by the DHSS whose staff we thank for their patient support.

\section{References}

${ }^{1}$ Second report from the Social Services Committee. Perinatal and neonatal mortality. Session 1979-80, HC 663-1, Vol 1. London: HMSO, 1980, 87-90.

${ }^{2}$ DHSS. Reply to the second report from the social services committee on perinatal and neonatal mortality. Cmnd 8084. London: HMSO, 1980, 11-12.

${ }^{3}$ NHS/DHSS Steering Group on Health Services Information. First report to the Secretary of State. London: HMSO, 1982.

${ }_{5}^{4}$ DHSS. Performance indicators. London: DHSS, 1985.

${ }^{5}$ Brown I, Elbourne D, Mutch L. Standard national perinatal data: a suggested minimum data set. Comm Med 1981; 3: 298-306. 
6 Thompson AM, Barron SL. A standard maternity information system. In: Chalmers I, McIlwaine G (eds). Perinatal audit and surveillance. London: RCOG, 1980.

${ }^{7}$ Mugford M, Mutch L, Elbourne D. Standard national perinatal data: suggestions for regular review of facilities for perinatal care within a regional health authority. Comm Med 1985; 7: 157-68.

${ }^{8}$ Bakketeig LS, Hoffman HJ, Sternthal PM. Obstetric service and perinatal mortality in Norway. Acta Obstet Gynecol Scand, Supplement 77: 1978.

${ }^{9}$ Bowes WA, Fryer GE, Ellis B. The use of standardised neonatal mortality ratios to assess the quality of perinatal care in Colorado. Am J Obstet Gynecol 1984; 148: 1067-73.

${ }^{10}$ Chase HC. A study of risks, medical care and infant mortality. Am J Public Health 1973; 63 supplement.

${ }^{11}$ Forbes JF, Boddy FA, Pickering R, Wyllie M. Perinatal mortality in Scotland 1970-1979. J Epidemiol Community Health 1982; 36: 282-8.

12 Corman H, Grossman M. Determinants of neonatal mortality rates in the US. J Health Econ 1985; 4: 213-36.

${ }^{13}$ Knox EG, Lancashire R, Armstrong EH. Perinatal mortality standards: construction and use of a health care performance indicator. $J$ Epidemiol Community Health 1986; 40: 193-204.

${ }^{14}$ Paneth N, Kiely JL, Wallenstein S, Marcus M, Pakter J, Susser M. Newborn intensive care and neonatal mortality in low birthweight infants. New Eng J Med 1982; 307: 149-55.

15 Williams RL. Measuring the effectiveness of perinatal medical care. Medical Care 1979; 17: 95-110.

${ }^{16}$ Hemminki E. Perinatal mortality distributed by type of hospital in the central hospital district of Helsinki, Finland. Scand J Social Medicine 1985; 13: 113-8.

${ }^{17}$ Rosenblatt RA, Reinker J, Schoemacle P. Is obstetrics safe in small hospitals? Lancet 1985: 429-32.

18 Arvidsson J, Eksmyr R. Cerebral palsy and perinatal deaths in geographically defined populations with different perinatal services. Dev Med Child Neurol 1984; 26: 709-16.

19 Eksmyr R. Early neonatal deaths in geographically defined populations with different organisation of medical care. Acta Paed Scand 1985; 74: 848-54.

${ }^{20}$ Eksmyr R. Geographically defined populations with different organisation of medical care. Comparison of perinatal risks. Acta Paed Scand 1985; 74: 855-60.

${ }^{21}$ Eksmyr R. Geographically defined populations with different organisation of medical care. Cause specific analysis of early neonatal deaths. Acta Paed Scand 1986; 75: $10-6$.

22 Feldstein MS. Economic analysis for health service efficiency. Amsterdam: North Holland, 1967.

${ }^{23}$ Lavers RY, Whynes DK. A production function analysis of English maternity hospitals. Socio Economic Planning and Science 1978; 12: 85-93.

${ }^{24}$ Stilwell JA. The Performance of Maternity Hospitals. Report to DHSS. Health Services Research Unit, University of Birmingham, 1981.

25 Wilcox A, Russell IT. Birthweight and perinatal mortality: III. Toward a new method of analysis. Int $J$ Epidemiol 1986; 16: 188-96.

${ }^{26}$ Macfarlane A, Mugford M. Birth counts: statistics of pregnancy and childbirth. Vol II. London: HMSO, 1984, 210.
${ }^{27}$ Central Management Services. Study of hospital-based midwives. Report no. CMS A6182. DHSS, London, 1984.

${ }^{28}$ Sunderland $\mathbf{R}$. Inaccurate coding corrupts medical information. Arch Dis Child 1985; 60: 593-4.

${ }^{29}$ Szczepura A, Mugford M, Stilwell JA. Information for decision makers at hospital level: an example of a graphical method of representing maternity unit statistics. $\mathrm{Br}$ Med J 1987; 294: 875-80.

${ }^{30}$ Lew RA, Day CL, Harrist TJ, Wood WC, Mihm MC. Multivariate analysis. Some guidelines for physicians. JAMA 1983; 249: 641-3.

31 Mutch L, Elbourne D. Locally based perinatal surveys. Report submitted to DHSS, December 1985. Oxford, NPEU.

32 Chalmers I. Enquiry into perinatal death: a report on national perinatal surveillance. Report submitted to DHSS, December 1984. Oxford, NPEU.

Accepted for publication January 1988

\section{Appendix}

RESULTS OF MULTIPLE REGRESSION ANALYSIS OF WMRHA MATERNITY HOSPITAL DATA FOR YEARS 1977-83

\section{Method and hypothesis}

The model being fitted by the SPSS-X stepwise procedure assumes a linear relationship of the form

$\mathrm{Yi}=\mathrm{b}_{\mathrm{o}}+\mathrm{b}_{1} \mathrm{X}_{\mathrm{i} 1}+\mathrm{b}_{2} \mathrm{X}_{\mathrm{i} 2}+\ldots+\mathrm{E}_{\mathrm{i}}$

The error term $E_{i}$ is assumed to have variance related to the number of births in unit $\mathrm{i}$. We assume that $\mathrm{E}(\mathrm{E})=0$

and that

Variance $(E) \propto \underline{1}_{n}$

Cases are therefore weighted according to the number at each unit.

The null hypothesis being tested is that of no linear association by $\mathrm{Y}$ and $\mathrm{X}_{1}, \mathrm{X}_{2}$ etc as considered together. This is expressed by a test of

(a) $R_{p}=0$ where $R_{p}$ is the multiple correlation coefficient

or

(b) $\mathbf{B}_{\mathrm{i}}=\mathbf{B}_{2}=\ldots=0$ where $\mathbf{B}_{\mathrm{i}}$ are population partial regression coefficients.

Regressions were performed as outlined in table A2 using variables as defined in table $\mathrm{A} 1$ and as described in the main text. Full results are presented below in tabular form, showing the number of units for which full data were available, variables selected in the regression for each year with their regression coefficients, the significance of the $F$ statistic $(p(F))$, the multiple correlation coefficient $\left(R^{2}\right)$, and the adjusted coefficient (Adj $\mathbf{R}^{2}$ ). 


\section{RESULTS}

(1) Analyses with dependent variable PNMR

(a) Explanatory variables: $O B P D M N T B<15$

\begin{tabular}{|c|c|c|c|c|c|c|c|c|c|}
\hline Year & $\begin{array}{l}\text { No. of } \\
\text { units } \\
N\end{array}$ & $\begin{array}{l}\text { Constant } \\
\text { term } \\
b_{o} \pm s_{0}\end{array}$ & $\begin{array}{l}\text { Variables } \\
X_{I}\end{array}$ & $\begin{array}{l}\text { selected in regression } \\
b_{1} \pm s_{1}\end{array}$ & $X_{2}$ & $b_{2} \pm S_{2}$ & $p(F)$ & $R^{2}$ & $\operatorname{Adj} R^{2}$ \\
\hline 77 & 16 & - & - & - & - & - & - & - & - \\
\hline 78 & 15 & - & - & - & - & - & - & - & - \\
\hline 79 & 15 & $6.13 \pm 2.01$ & $T B<15$ & $0.85 \pm 0.18$ & - & - & 0.0004 & 0.626 & 0.596 \\
\hline 80 & 18 & $7 \cdot 84 \pm 2 \cdot 16$ & TB $<15$ & $0.52 \pm 0.18$ & - & - & 0.009 & 0.353 & 0.313 \\
\hline 81 & 16 & $7.27 \pm 1.73$ & $\mathrm{~TB}<15$ & $0.46 \pm 0.17$ & - & - & 0.017 & 0.343 & 0.296 \\
\hline 82 & 16 & - & - & - & - & - & - & - & - \\
\hline 83 & 15 & $3.62 \pm 3.34$ & $\mathrm{~TB}<15$ & $0.77 \pm 0.31$ & - & - & 0.026 & 0.325 & 0.273 \\
\hline
\end{tabular}

(b) Explanatory variables: $O B P D M N T B<25$

\begin{tabular}{|c|c|c|c|c|c|c|c|c|c|}
\hline Year & $\begin{array}{l}\text { No. of } \\
\text { units } \\
N\end{array}$ & $\begin{array}{l}\text { Constant } \\
\text { term } \\
b_{0} \pm s_{0}\end{array}$ & $\begin{array}{l}\text { Variables } \\
X_{I}\end{array}$ & $\begin{array}{l}\text { selected in regression } \\
b_{I} \pm s_{I}\end{array}$ & $X_{2}$ & $b_{2} \pm S_{2}$ & $p(F)$ & $R^{2}$ & $\operatorname{Adj} R^{2}$ \\
\hline 77 & 16 & - & - & - & - & - & - & - & - \\
\hline 78 & 15 & $7.91 \pm 4.57$ & $\mathrm{~TB}<25$ & $0.17 \pm 0.05$ & PD & $-0.34 \pm 0.13$ & 0.009 & 0.547 & 0.471 \\
\hline 79 & 15 & $5.42 \pm 3.78$ & TB $<25$ & $0.12 \pm 0.04$ & - & - & 0.022 & 0.343 & 0.293 \\
\hline 80 & 18 & - & - & - & - & - & - & - & - \\
\hline 81 & 16 & - & - & - & - & - & - & - & - \\
\hline 82 & 16 & $8.06 \pm 2.67$ & TB $<25$ & $0.12 \pm 0.03$ & PD & $-0.22 \pm 0.08$ & 0.006 & 0.542 & 0.472 \\
\hline 83 & 15 & - & - & - & - & - & - & - & - \\
\hline
\end{tabular}

(c) Explanatory variables: $O B P D S C M T B<15 T B<25$

\begin{tabular}{|c|c|c|c|c|c|c|c|c|c|}
\hline Year & $\begin{array}{l}\text { No. of } \\
\text { units } \\
N\end{array}$ & $\begin{array}{l}\text { Constant } \\
\text { term } \\
b_{0} \pm s_{0}\end{array}$ & $\begin{array}{l}\text { Variables } \\
X_{I}\end{array}$ & $\begin{array}{l}\text { selected in regression } \\
b_{1} \pm s_{1}\end{array}$ & $X_{2}$ & $b_{2} \pm S_{2}$ & $p(F)$ & $R^{2}$ & $\operatorname{Adj} R^{2}$ \\
\hline $\begin{array}{l}77 \\
78 \\
79 \\
80 \\
81 \\
82 \\
83\end{array}$ & $\begin{array}{l}16 \\
15 \\
15 \\
18 \\
16 \\
16 \\
15\end{array}$ & $\begin{array}{l}- \\
7.91 \pm 4.57 \\
6.13 \pm 2.01 \\
7.84 \pm 2 \cdot 16 \\
7.27 \pm 1 \cdot 73 \\
8.06 \pm 2.67 \\
3.62 \pm 3.34\end{array}$ & $\begin{array}{l}- \\
\text { TB }<25 \\
\text { TB }<15 \\
\text { TB }<15 \\
\text { TB }<15 \\
\text { TB }<25 \\
\text { TB }<15\end{array}$ & $\begin{array}{l}- \\
0.17 \pm 0.05 \\
0.85 \pm 0.18 \\
0.52 \pm 0.18 \\
0.46 \pm 0.17 \\
0.12 \pm 0.03 \\
0.77 \pm 0.31\end{array}$ & $\begin{array}{l}\overline{\text { PD }} \\
- \\
- \\
\overline{\text { PD }} \\
-\end{array}$ & $\begin{array}{l}- \\
-0.34 \pm 0.13 \\
- \\
- \\
-0.22 \pm 0.08 \\
-\end{array}$ & $\begin{array}{l}- \\
0.009 \\
0.0004 \\
0.009 \\
0.017 \\
0.006 \\
0.026\end{array}$ & $\begin{array}{l}- \\
0.547 \\
0.625 \\
0.353 \\
0.343 \\
0.542 \\
0.325\end{array}$ & $\begin{array}{l}- \\
0.471 \\
0.597 \\
0.313 \\
0.296 \\
0.471 \\
0.273\end{array}$ \\
\hline
\end{tabular}

(d) Explanatory variables: $O B P D M N T B<15 T B<25$

\begin{tabular}{|c|c|c|c|c|c|c|c|c|c|}
\hline Year & $\begin{array}{l}\text { No. of } \\
\text { units } \\
N\end{array}$ & $\begin{array}{l}\text { Constant } \\
\text { term } \\
b_{o} \pm s_{0}\end{array}$ & $\begin{array}{l}\text { Variables } \\
X_{I}\end{array}$ & $\begin{array}{l}\text { selected in regression } \\
b_{I} \pm s_{I}\end{array}$ & $X_{2}$ & $b_{2} \pm S_{2}$ & $p(F)$ & $R^{2}$ & $\operatorname{Adj} R^{2}$ \\
\hline $\begin{array}{l}77 \\
78 \\
79 \\
80 \\
81 \\
82 \\
83\end{array}$ & $\begin{array}{l}16 \\
15 \\
15 \\
18 \\
16 \\
16 \\
15\end{array}$ & $\begin{array}{l}- \\
7.91 \pm 4.57 \\
6.13 \pm 2.01 \\
7.84 \pm 2.16 \\
7.27 \pm 1.73 \\
8.06 \pm 2.67 \\
3.62 \pm 3.34\end{array}$ & $\begin{array}{l}- \\
T B<25 \\
T B<15 \\
T B<15 \\
T B<15 \\
T B<25 \\
T B<15\end{array}$ & $\begin{array}{l}- \\
0.17 \pm 0.05 \\
0.85 \pm 0.18 \\
0.52 \pm 0.18 \\
0.46 \pm 0.17 \\
0.12 \pm 0.03 \\
0.77 \pm 0.31\end{array}$ & $\begin{array}{l}- \\
\text { PD } \\
- \\
- \\
- \\
\text { PD } \\
-\end{array}$ & $\begin{array}{l}- \\
-0.34 \pm 0.13 \\
- \\
- \\
- \\
-0.22 \pm 0.08 \\
-\end{array}$ & $\begin{array}{l}- \\
0.009 \\
0.0004 \\
0.009 \\
0.017 \\
0.006 \\
0.026\end{array}$ & $\begin{array}{l}- \\
0.547 \\
0.625 \\
0.353 \\
0.342 \\
0.542 \\
0.325\end{array}$ & $\begin{array}{l}- \\
0.471 \\
0.597 \\
0.313 \\
0.295 \\
0.471 \\
0.273\end{array}$ \\
\hline
\end{tabular}

(e) Explanatory variables: $O B P D P D / L B W M N T B<15 T B<25$

\begin{tabular}{|c|c|c|c|c|c|c|c|c|c|}
\hline Year & $\begin{array}{l}\text { No. of } \\
\text { units } \\
N\end{array}$ & $\begin{array}{l}\text { Constant } \\
\text { term } \\
b_{o} \pm s_{0}\end{array}$ & $\begin{array}{l}\text { Variables } \\
X_{I}\end{array}$ & $\begin{array}{l}\text { selected in regression } \\
b_{1} \pm s_{1}\end{array}$ & $x_{2}$ & $b_{2} \pm S_{2}$ & $p(F)$ & $R^{2}$ & $\operatorname{Adj} R^{2}$ \\
\hline $\begin{array}{l}77 \\
78 \\
79 \\
80 \\
81 \\
82 \\
83\end{array}$ & $\begin{array}{l}16 \\
15 \\
15 \\
18 \\
16 \\
16 \\
15\end{array}$ & $\begin{array}{r}- \\
22 \cdot 76 \pm 2 \cdot 20 \\
6 \cdot 13 \pm 2 \cdot 01 \\
7 \cdot 84 \pm 2 \cdot 16 \\
7.27 \pm 1 \cdot 73 \\
18.6 \pm 1.98 \\
3.62 \pm 3.34\end{array}$ & $\begin{array}{l}- \\
\text { PD } / \text { LBW } \\
\text { TB }<15 \\
\text { TB }<15 \\
\text { TB }<15 \\
\text { PD } / \text { LBW } \\
\text { TB }<15\end{array}$ & $\begin{aligned}-301.63 & \pm 88.58 \\
0.85 & \pm 0.18 \\
0.52 & \pm 0.18 \\
0.46 & \pm 0.17 \\
-205.53 & \pm 67.94 \\
0.77 & \pm 0.31\end{aligned}$ & $\begin{array}{l}- \\
- \\
- \\
- \\
- \\
-\end{array}$ & $\begin{array}{l}- \\
- \\
- \\
- \\
- \\
-\end{array}$ & $\begin{array}{l}\overline{0.005} \\
0.0004 \\
0.009 \\
0.017 \\
0.009 \\
0.026\end{array}$ & $\begin{array}{l}- \\
0.471 \\
0.625 \\
0.353 \\
0.343 \\
0.395 \\
0.325\end{array}$ & $\begin{array}{l}- \\
0.431 \\
0.597 \\
0.313 \\
0.296 \\
0.352 \\
0.273\end{array}$ \\
\hline
\end{tabular}


(2) Analyses with dependent variable SPNMR

Explanatory variables: $O B P D M N T B<15 T B<25$

\begin{tabular}{|c|c|c|c|c|c|c|c|c|c|}
\hline Year & $\begin{array}{l}\text { No. of } \\
\text { units } \\
N\end{array}$ & $\begin{array}{l}\text { Constant } \\
\text { term } \\
b_{o} \pm s_{O}\end{array}$ & $\begin{array}{l}\text { Variables } \\
X_{1}\end{array}$ & $\begin{array}{l}\text { selected in regression } \\
b_{I} \pm s_{I}\end{array}$ & $X_{2}$ & $b_{2} \pm S_{2}$ & $p(F)$ & $R^{2}$ & $\operatorname{Adj} R^{2}$ \\
\hline 77 & 16 & - & - & - & - & - & - & - & - \\
\hline 78 & 15 & $7 \cdot 16 \pm 4 \cdot 38$ & $\mathrm{~TB}<25$ & $0.16 \pm 0.005$ & PD & $-0.27 \pm 0.12$ & 0.016 & 0.500 & 0.417 \\
\hline 79 & 15 & $6.54 \pm 1.90$ & $\mathrm{~TB}<15$ & $0.71 \pm 0.17$ & - & - & 0.001 & 0.565 & 0.531 \\
\hline 80 & 18 & $7.86 \pm 0.45$ & $\mathrm{~TB}<15$ & $0.45 \pm 0.19$ & - & - & 0.027 & 0.270 & 0.224 \\
\hline 81 & 16 & $5.69 \pm 1.70$ & $\mathrm{~TB}<15$ & $0.52 \pm 0.17$ & - & - & 0.007 & 0.416 & 0.374 \\
\hline 82 & 16 & $7 \cdot 27 \pm 2.64$ & $\mathrm{~TB}<25$ & $0.12 \pm 0.03$ & PD & $-0.20 \pm 0.08$ & 0.008 & 0.521 & 0.448 \\
\hline 83 & 15 & - & - & - & - & - & - & - & - \\
\hline
\end{tabular}

(3) Analyses with dependent variable PNMRCA

Explanatory variables: $O B P D P D / L B W M N T B<15 T B<25$

\begin{tabular}{|c|c|c|c|c|c|c|c|c|c|}
\hline Year & $\begin{array}{l}\text { No. of } \\
\text { units } \\
N\end{array}$ & $\begin{array}{l}\text { Constant } \\
\text { term } \\
b_{o} \pm s_{o}\end{array}$ & $\begin{array}{l}\text { Variables } \\
X_{I}\end{array}$ & $\begin{array}{l}b_{1} \pm s_{1}\end{array}$ & $X_{2}$ & $b_{2} \pm S_{2}$ & $p(F)$ & $R^{2}$ & $\operatorname{Adj} R^{2}$ \\
\hline 77 & 16 & $9 \cdot 75 \pm 2 \cdot 18$ & $\mathrm{~TB}<15$ & $0.50 \pm 0.17$ & - & - & 0.009 & 0.393 & 0.349 \\
\hline 78 & 15 & $19 \cdot 8 \pm 2.0$ & PD/LBW & $-268 \pm 82$ & - & - & 0.006 & 0.45 & 0.41 \\
\hline 79 & 15 & $4.64 \pm 2.06$ & $\mathrm{~TB}<15$ & $0.80 \pm 0.19$ & - & - & 0.0009 & 0.587 & 0.555 \\
\hline 80 & 18 & $6.75 \pm 1.95$ & TB $<15$ & $0.42 \pm 0.16$ & - & - & 0.017 & 0.307 & 0.263 \\
\hline 81 & 16 & - & - & - & - & - & - & - & - \\
\hline 82 & 16 & $16.5 \pm 1.8$ & PD/LBW & $-195 \pm 61$ & - & - & 0.006 & 0.42 & 0.38 \\
\hline 83 & 13 & $2.42 \pm 3.22$ & $\mathrm{~TB}<15$ & $0.74 \pm 0.31$ & - & - & 0.04 & 0.33 & 0.267 \\
\hline
\end{tabular}

(4) Analysis with dependent variable $S B$

Explanatory variables: $O B P D M N T B<15 T B<25$

\begin{tabular}{|c|c|c|c|c|c|c|c|c|c|}
\hline Year & $\begin{array}{l}\text { No. of } \\
\text { units } \\
N\end{array}$ & $\begin{array}{l}\text { Constant } \\
\text { term } \\
b_{o} \pm s_{o}\end{array}$ & $\begin{array}{l}\text { Variables } \\
X_{I}\end{array}$ & $\begin{array}{l}\text { selected in regression } \\
b_{1} \pm s_{1}\end{array}$ & $X_{2}$ & $b_{2} \pm S_{2}$ & $p(F)$ & $R^{2}$ & $\operatorname{Adj} R^{2}$ \\
\hline 77 & 16 & - & - & - & .. & - & - & $\ldots$ & - \\
\hline 78 & 15 & $3 \cdot 83 \pm 2 \cdot 10$ & TB $<15$ & $0.52 \pm 0.19$ & - & - & 0.015 & 0.375 & 0.327 \\
\hline 79 & 15 & - & - & - & - & - & - & - & - \\
\hline 80 & 18 & - & - & - & - & - & - & - & - \\
\hline 81 & 16 & - & - & - & - & - & - & - & - \\
\hline 82 & 16 & - & - & - & - & - & - & - & - \\
\hline 83 & 15 & - & - & - & - & - & - & - & - \\
\hline
\end{tabular}

(5) Analysis with dependent variable $F W D$

(a) Explanatory variables: $O B P D M N T B<15 T B<25$

\begin{tabular}{|c|c|c|c|c|c|c|c|c|c|}
\hline Year & $\begin{array}{l}\text { No. of } \\
\text { units } \\
N\end{array}$ & $\begin{array}{l}\text { Constant } \\
\text { term } \\
b_{o} \pm s_{O}\end{array}$ & $\begin{array}{l}\text { Variables } \\
X_{1}\end{array}$ & $\begin{array}{l}\text { selected in regression } \\
b_{1} \pm s_{1}\end{array}$ & $x_{2}$ & $b_{2} \pm S_{2}$ & $p(F)$ & $R^{2}$ & $\operatorname{Adj} R^{2}$ \\
\hline 77 & 16 & $7.66 \pm 2.02$ & PD & $-0.16 \pm 0.06$ & $T B<15$ & $0 \cdot 26 \pm 0 \cdot 10$ & 0.004 & 0.582 & 0.517 \\
\hline 78 & 15 & $4 \cdot 22 \pm 3.06$ & PD & $-0.26 \pm 0.08$ & TB $<25$ & $0.08 \pm 0.04$ & 0.014 & 0.507 & 0.425 \\
\hline 79 & 15 & $0.91 \pm 2.09$ & $\mathrm{~TB}<15$ & $0.47 \pm 0.19$ & - & - & 0.028 & 0.320 & $0 \cdot 268$ \\
\hline 80 & 18 & - & - & - & - & - & - & - & - \\
\hline 81 & 16 & - & - & - & - & - & - & - & - \\
\hline 82 & 16 & $2.51 \pm 1.52$ & $\mathrm{~TB}<25$ & $0.09 \pm 0.02$ & PD & $-0.21 \pm 0.48$ & 0.0004 & 0.700 & 0.654 \\
\hline 83 & 15 & - & - & - & - & - & - & - & - \\
\hline
\end{tabular}

(b) Explanatory variables: $O B P D P D / L B W M N T B<15 T B<25$

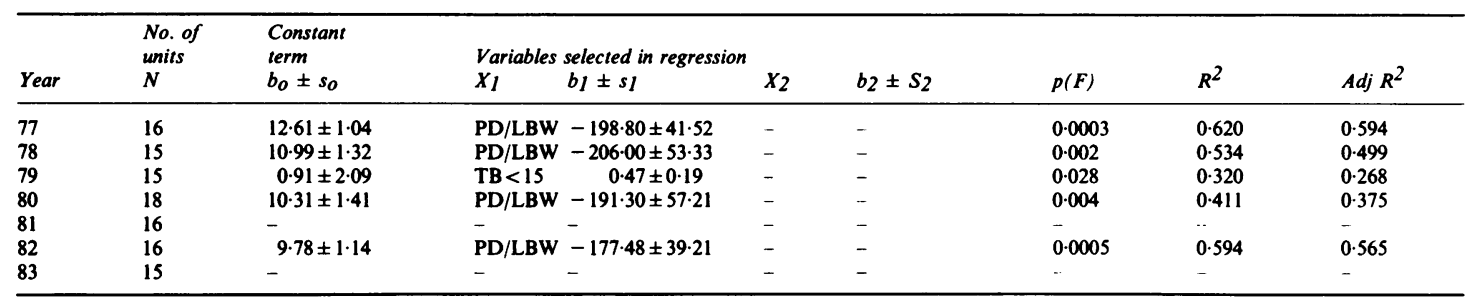


(6) Analysis with dependent variable FWDCA

Explanatory variables: $O B P D P D / L B W M N T B<15 T B<25$

\begin{tabular}{|c|c|c|c|c|c|c|c|c|c|}
\hline Year & $\begin{array}{l}\text { No. of } \\
\text { units } \\
N\end{array}$ & $\begin{array}{l}\text { Constant } \\
\text { term } \\
b_{o} \pm s_{o}\end{array}$ & $\begin{array}{l}\text { Variables } \\
X_{1}\end{array}$ & $\begin{array}{l}\text { selected in regression } \\
b_{1} \pm s_{1}\end{array}$ & $x_{2}$ & $b_{2} \pm S_{2}$ & $p(F)$ & $R^{2}$ & $\operatorname{Adj} R^{2}$ \\
\hline 77 & 15 & $11 \cdot 6 \pm 1 \cdot 1$ & PD/LBW & $-196 \pm 46$ & - & - & 0.0009 & 0.58 & 0.55 \\
\hline 78 & 15 & $9.7 \pm 1.3$ & PD/LBW & $-189 \pm 53$ & - & - & 0.0034 & 0.49 & 0.46 \\
\hline 79 & 15 & $0.74 \pm 2$ & TB $<15$ & $0.4 \pm 0.18$ & - & - & 0.048 & 0.27 & 0.21 \\
\hline 80 & 18 & $8.2 \pm 1.2$ & PD/LBW & $-157 \pm 50$ & - & - & 0.0068 & $0 \cdot 38$ & 0.34 \\
\hline 81 & 16 & - & - & - & - & - & - & - & - \\
\hline 82 & 16 & $8.5 \pm 1.0$ & PD/LBW & $-170 \pm 36$ & - & - & 0.0003 & 0.62 & 0.59 \\
\hline 83 & 13 & - & - & - & - & - & - & - & - \\
\hline
\end{tabular}

Table A1 Definition of variables for each regression analysis

\begin{tabular}{|c|c|}
\hline PNMR & $\begin{array}{l}\text { Stillbirths and deaths (age } 0-6 \text { days) recorded at hospital of } \\
\text { birth. Per } 1000 \text { total births at that unit }\end{array}$ \\
\hline SPNMR & As above, for singleton births and deaths only \\
\hline PNMRCA & $\begin{array}{l}\text { PNMR rate for non-malformed singleton and multiple births per } \\
1000 \text { total births at that unit }\end{array}$ \\
\hline SB & $\begin{array}{l}\text { Stillbirth rate for all births recorded at hospital of birth per } \\
1000 \text { total births }\end{array}$ \\
\hline FWD & Deaths age $0-6$ days per 1000 total births \\
\hline FWDCA & $\begin{array}{l}\text { First week deaths for non-malformed singleton and multiple } \\
\text { births per } 1000 \text { livebirths at that unit }\end{array}$ \\
\hline OB & $\begin{array}{l}\text { Total number of obstetric medical staff (head count), all grades, } \\
\text { per } 10000 \text { total births }\end{array}$ \\
\hline PD & $\begin{array}{l}\text { Total number of paediatric medical staff (head count), all } \\
\text { grades, per } 10000 \text { total births }\end{array}$ \\
\hline PD/LBW & Total number of paediatric medical staff per low weight birth \\
\hline MN & $\begin{array}{l}\text { Total number of qualified nursing and midwifery staff, whole } \\
\text { time equivalent per } 1000 \text { births }\end{array}$ \\
\hline SCM & $\begin{array}{l}\text { Total number of qualified midwifery staff, whole time } \\
\text { equivalent per } 1000 \text { births }\end{array}$ \\
\hline $\mathrm{TB}<15$ & Percentage of total births weighing $1500 \mathrm{~g}$ or less \\
\hline $\mathrm{TB}<25$ & Percentage of total births weighing $2500 \mathrm{~g}$ or less \\
\hline
\end{tabular}

Table A2 Summary of variables included in the regression analyses

\begin{tabular}{lllllll}
\hline $\begin{array}{lllll}\text { Analysis } \\
\text { series }\end{array}$ & $\begin{array}{l}\text { Dependent } \\
\text { variable }\end{array}$ & \multicolumn{5}{l}{ Possible explanatory variables } \\
\hline la & PNMR & OB & PD & MN & TB $<15$ & \\
b & PNMR & OB & PD & MN & TB $<25$ & \\
c & PNMR & OB & PF & SCM & TB $<15$ & TB $<25$ \\
d & PNMR & OB & PD & MN & TB $<15$ & TB $<25$ \\
e & PNMR & OB PD & PD/LBW & MN & TB $<15$ & TB $<25$ \\
2 & SPNMR & OB & PD & MN & TB $<15$ & TB $<25$ \\
3 & PNMRCA & OB PD & PD/LBW & MN & TB $<15$ & TB $<25$ \\
4 & SB & OB & PD & MN & TB $<15$ & TB $<25$ \\
5a & FWD & OB & PD & MN & TB $<15$ & TB $<25$ \\
b & FWD & OB PD & PD/LBW & MN & TB $<15$ & TB $<25$ \\
6 & FWDCA & OB PD & PD/LBW & MN & TB $<15$ & TB $<25$ \\
\hline
\end{tabular}

